\title{
Outcome of myringoplasty in dry and wet ear - a comparative study
}

\author{
Gautam Dhar ${ }^{1}$, Bijan Basak ${ }^{2}$, Ganesh Chandra Gayen ${ }^{2}$, Ritam Ray ${ }^{3}$ \\ 1. Associate professor, Department of Community Medicine, Assistant directer of Medical Education, Dept. of \\ Health \& Family welfare, Govt of West Bengal, Swasthya Bhawan, GN-29, Sector-5, Salt Lake City, \\ Kolkata-700091, West Bengal, India \\ 2. Assistant professor, Dept. of ENT, Burdwan Medical College \& Hospital, P.O. - Rajbati, Burdwan - 713104, \\ West Bengal, India \\ 3. RMO-cum-clinical tutor, Dept. of ENT, Burdwan Medical College \& Hospital, P.O. - Rajbati, Burdwan- \\ 713104, West Bengal, India
}

\begin{abstract}
:
Objective: To compare the outcome of myringoplasty in dry and wet ears suffering from Chronic suppurative otitis media with central perforation. Study design: Prospective study. Setting: Department of E.N.T, Burdwan Medical College \& Hospital. Methods :100 patients with Chronic suppurative otitis media with central perforation ( 50 dry and 50 wet perforations) undergone myringoplasty by underlay technique taking temporalis fascia through postaural approach under local anaesthesia. Wet ear had culture negative mucoid discharge. The outcome of the study compared.

Conclusion: Presence of mucoid discharge at the time of surgery does not interfere much with the result of myringoplasty. Although the success rate in dry ear is bit higher ( $P$ value $>0.05)$, there is no significant difference in the success rate in both dry ear and wet ear.
\end{abstract}

Key Words: Chronic suppurative otitis media ; Central perforation ; Dry ear ; Wet ear ; Myringoplasty

\section{Introduction}

Chronic suppurative otitis media is a very common ear disease for which patients attend otolaryngology clinic. Most of the times, they present with discharging ear. In this situation, Otolaryngologists are always in a debate - whether to operate or not at this stage. Previously, it was thought that the success rate of myringoplasty in actively discharging ear is much lower that that of dry ear. Keeping this in mind, we have conducted a study to compare the outcome of myringoplasty in dry and wet ear .

\section{Materials And Methods}

This study was carried out in the Dept of ENT, Burdwan Medical College \& Hospital. It comprises of 100 patients with Chronic suppurative otitis media with central perforation with 50 patients each in dry and wet ear group over a period of 1 years from May, 2011 to April, 2012. All the patients were examined carefully after admission.

\section{Inclusion criteria :}

1. Chronic suppurative otitis media with central perforation (small, medium and subtotal perforation)

2. Age : between 14 to 45 years

3. Sex : both male and female.

4. All patient with wet ear having a mucoid discharge with negative on culture.

5. No evidence of active infection in nose and throat.

6. Hearing loss $<40 \mathrm{~dB}$

\section{Exclusion criteria :}

1. Age : less than 14 years \& more than 45 years

2. Patients with total perforation and cholesteatoma

3. Patients with sensorineural hearing loss

4. Revision tympanoplasty cases

5. Complicated otitis media

All patients under the study were undergone complete physical examination, laboratory assessment (routine hematology, blood biochemistry), standard 12 lead ECG within previous one week of surgery. Complete otolaryngological examination done to exclude other pathologies. In wet ear cases, routinely culture of aural discharge sent to exclude bacterial infection. In all cases, examination under operating microscope were 
done to assess the site and size of perforation and middle ear mucosa. After taking written informed consent, all patients undergone myringoplasty through postaural approach by underlay technique taking temporalis fascia as a graft material. All the patients were followed up at 2 wks, 4 wks, 6 wks and 8 wks and 6 months after surgery. Aim of our study was to assess the graft takeup rate between these two groups.

\section{Results}

Out of 100 cases , 50 cases had dry ear and rest cases had wet ear. In 48 cases (96\%) out of 50 dry ear, perforation healed and 2 (4\%) case failed to heal. Whereas, in wet ear, perforation healed in 42 cases (84\%) out of 50 cases [ Table -1 ] .

Out of 50 dry perforation cases, 24 (48\%)patients had subtotal perforation and rest 26 (52\%) patients had small and medium size perforation. 2 failure cases were among those 24 subtotal perforations. All small and medium size dry perforations healed nicely. [ Table -2 ] .

Out of 50 wet perforation cases, $28(56 \%)$ patients had subtotal perforation and rest $22(44 \%)$ patients had small and medium size perforation. 6 failure cases were among those 28 subtotal perforations. 2 failure cases were among those 22 small and medium size wet perforations.

\section{Discussion}

CSOM is a very common condition characterised by chronic inflammation of the mucoperiosteal lining of middle ear cleft. Of the main two types, tubotympanic type is more common and it is characterised by a perforation in the pars tensa of tympanic membrane. Perforation of the tympanic membrane primarily results from middle ear infections, trauma or iatrogenic causes etc. This type of disease presents with discharge from ear and hearing loss and patients are advised to avoid water activities.

Spontaneous healing of chronic tympanic membrane perforation is uncommon and medical management is not effective in this regard. Hence, surgical intervention is necessary for closure of perforation.

Myringoplasty is a safe and effective technique to improve the quality of life of patients, avoiding continuous infections and allowing them contact with water. Introduced by Berthold [1], myringoplasty was further developed by Wullstein [2] and Zollner [3]. Ideal candidates for myringoplasty should have central perforation with normal middle ear mucosa, intact ossicular chain and good cochlear reserve.

Myringoplasty in dry ear having very good result. But in most of the times patients present with discharging ear. It is a common belief that surgery in a wet ear seems to have a poorer result. In our study, we had a success rate of $96 \%$ in dry perforation as compared to the $84 \%$ in wet cases.

In a prospective study, outcome of type I tympanoplasty done on 100 patients with dry and wet ears was compared. The study showed that the presence of ear discharge at the time of surgery did not interfere with the results, but discharge should be mucoid and scanty [4] .

Another study conducted on 50 patients with mucoid discharge undergoing myringoplasty, to find the efficacy of graft uptake, showed that primary closure of perforation was seen in $84 \%$ cases. It showed that the presence of ear discharge at the time of surgery did not influence the results of surgery [5] [ Table - 3 ] .

Success rate of myringoplasty in various studies is given in table $3[6,7,8,9]$. In our study, closure rate in dry perforation is much high and even in wet cases the success rate is $84 \%$ which is compatible to other studies.

\section{Tables}

Table - 1 Success rate of myringoplasty

\begin{tabular}{|l|l|l|}
\hline Graft taken up & Dry perforation $(\mathbf{n}=50)$ & Wet perforation(n=50) \\
\hline Yes & $\mathbf{4 8}(\mathbf{9 6 \%})$ & $\mathbf{4 2}(\mathbf{8 4 \%})$ \\
\hline No & $\mathbf{2 ( 4 \% )}$ & $\mathbf{8}(\mathbf{1 6 \%})$ \\
\hline
\end{tabular}

Chi squared equals 2.778 with 1 degrees of freedom. The two tailed $p$ value equals 0.0956

Table - 2 Size of perforation

\begin{tabular}{|l|l|l|}
\hline Size of perforation & Dry perforation $(\mathrm{n}=50)$ & Wet perforation $(\mathrm{n}=50)$ \\
\hline Subtotal & $\mathbf{2 4}(\mathbf{4 8 \%})$ & $\mathbf{2 8}(\mathbf{5 6 \%})$ \\
\hline Small to medium & $\mathbf{2 6}(52 \%)$ & $\mathbf{2 2}(\mathbf{4 4 \%})$ \\
\hline
\end{tabular}

Chi squared equals 0.361 with 1 degrees of freedom.

The two tailed p value equals 0.5482 
Table - 3Success rate of myringoplasty in various studies

\begin{tabular}{|l|l|l|}
\hline Reference & No. of cases & Closure rate \\
\hline Kotecha et al [6] & $\mathbf{1 0 7 0}$ & $\mathbf{8 2 \%}$ \\
\hline Wielinga et al [7] & $\mathbf{5 5 5}$ & $\mathbf{8 8 \%}$ \\
\hline Lee et al [8] & $\mathbf{4 2 3}$ & $\mathbf{6 4 \%}$ \\
\hline Black and Wormald et al [9] & $\mathbf{2 1 1}$ & $\mathbf{7 8 \%}$ \\
\hline Raja, Vidit et al & $\mathbf{5 0}$ & $\mathbf{8 4 \%}$ \\
\hline
\end{tabular}

\section{Conclusion}

Presence of mucoid discharge which is culture negative at the time of surgery is not a contraindication for surgery as it does not interfere much with the result of myringoplasty. There is no significant difference in the success rate in both dry ear and culture negative wet ear in our study.

\section{References}

[1] Berthold E. Ueber myringoplastik. Wier Med Bull. 1878;1:627-627.

[2] Wullstein H. Theory and practice of myringoplasty. Laryngoscope. 1956;66:1076-93.

[3] Zollner F. The principles of plastic surgery of the sound-conducting apparatus. J Laryngol Otol. 1955;69:637-652.

[4] Nagle S K, Jagade M V, Gandhi S R et al: Comparative study of outcome of Type I Tympanoplasty in dry and wet ear. Indian J Otolaryngol Head Neck Surg 2009;61:138-140.

[5] Raj A, Vidit: Review of patients undergoing wet myringoplasty. Indian journal of otology 1999;5(3):134-136.

[6] 6.Kotacha B, Fowler S, Topham J,. Myringoplasty a prospective audit study. Clinical otolaryngology and allied sciences.1999;24 : 126-9

[7] Wielinga EW, Derks AM, Cremers CW. Tympanosclerosis in the tympanic membrane : influence on outcome of myringoplasty. American journal of otology.1995; 16: 811-4

[8] 8.Lee P, Kelly G, Mills RP. Myringoplasty : does the size of the perforation matter ? Clinical otolaryngology and allied sciences.2002;27: 331-4

[9] 9.Black JH, Wormald PJ. Myringoplasty effects on hearing and contributing factors. South African medical journal. $1995 ; 85$ : $41-3$

\section{Abbreviations}

ECG - Electrocardiogram

CSOM - Chronic suppurative otitis media 